\title{
A note on optimal taxation in the presence of externalities
}

\author{
Wojciech Kopczuk* \\ Department of Economics, University of British Columbia, \#997-1873 East Mall, Vancouver BC, Canada V6T 1Z1
}

Received 28 August 2002; accepted 16 December 2002

\begin{abstract}
I consider the problem of optimal taxation with externalities in a general setup encompassing most of optimal taxation models found in the literature. It is demonstrated that when direct taxation of externalities is possible, optimal taxes can be expressed as the sum of the optimal Pigouvian taxes and the optimal taxes in a related problem without externalities, regardless of what other tax instruments are available. This result generalizes the so-called 'Principle of Targeting'.
\end{abstract}

(C) 2003 Elsevier Science B.V. All rights reserved.

Keywords: Optimal taxation; Externalities; Second-best

JEL classification: $\mathrm{H} 21 ; \mathrm{H} 23$

One of the main results of the literature on optimal taxation in the presence of externalities (e.g., Sandmo, 1975; Ng, 1980; Bovenberg and van der Ploeg, 1994) is the 'additivity property': the presence of an externality affects only the formula for the tax on the externality generating commodity, and it does not affect the optimal taxes imposed on other goods. ${ }^{1}$ Dixit (1985) referred to this result as an example of a more general 'principle of targeting': one should correct the externality by targeting its source directly. This result has powerful implications for designing tax policy, because it implies that correcting externalities may be done on an ad hoc basis by taxing suspect commodities, without relying on other components of the tax system to address this problem. However, it was not obvious how general this principle is, because all previous papers on the topic considered restricted

*Tel.: + 1-604-822-3223; fax: + 1-604-822-5915.

E-mail address: wkopczuk@nber.org (W. Kopczuk).

${ }^{1}$ This result requires that it is possible to tax the good generating the externality. Green and Sheshinsky (1976) construct an example when such a tax is not feasible and the property fails. They consider two individuals whose consumptions affect the other person and assume that it is not possible to impose different taxes on them. In the framework of this paper, they introduce two different externalities that may not be targeted separately. 
and arbitrary sets of tax instruments. As a result, it was not clear if this prescription applies in practice.

I demonstrate that the Principle of Targeting is very general: as long as it is possible to tax directly the externality generating commodity, the Principle holds regardless of what other tax instruments are available. In fact, one can build the following policy prescription: correct the externality directly using the Pigouvian tax (imposed on the dirty commodity), then find and apply the optimal taxes while ignoring the externality but using prices corrected by the Pigouvian tax and taking into account that some revenue is collected by it. ${ }^{2,3}$

\section{The principle of targeting}

To show the generality of the Principle of Targeting, consider the following optimal taxation problem containing an 'atmospheric' externality (i.e., an externality that is caused by the total consumption of the 'dirty' good; it affects individual objective functions, but it is taken as given when decisions are made):

$$
\max _{t, T} v(T, t ; P, p ; X(t, T ; P, p)) \quad \text { s.t. } \quad R=I(T, t, P, p)+t X(t, T ; P, p),
$$

where $v(\cdot)$ is the objective function, $X(\cdot)$ is the aggregate level of consumption of the externality generating good, $t$ is the tax imposed on this good, ${ }^{4} p$ is the price of this good, $T$ is the vector of all other tax instruments, ${ }^{5} P$ is the vector of other parameters (e.g., prices), $R$ is the exogenous revenue requirement and $I(\cdot)$ is the revenue collected by taxes other than $t$, given values of instruments and parameters.

The problem (1) is quite general. Objective functions that can be cast in this framework include an indirect utility function of the representative individual, social welfare with a continuum of types obtained by using some aggregating welfare function, and a profit function of the firm. The specification of tax revenue allows to incorporate many different types of taxes, in particular it does not require taxes to be linear. The only serious restriction is that taxation of the good generating the externality is possible.

For example, the nonlinear income and commodity taxation problem considered by Cremer et al. (1998) can be expressed in this way. To see it, interpret $v(\cdot)$ as the social welfare function evaluated at self-selected maximized utility levels (given taxes and parameters) of each type, augmented by the presence of the externality. In this context, the self-selection constraint is incorporated in individual maximization problems, and thus it is not a relevant constraint for the social planner. $I(\cdot)$ is the revenue collected by both the income tax and all commodity taxes except for the tax on the 'dirty'

\footnotetext{
${ }^{2}$ The actual process of finding the solution is more complicated, as the two parts of it are interrelated and the value of the Pigouvian tax may not be known before the full problem is solved.

${ }^{3}$ The problem I consider is a partial equilibrium one. Bovenberg and de Mooij (1994), Bovenberg and Goulder (1996) and Fullerton (1997) consider environmental taxes in general equilibrium contexts but under restricted sets of instruments.

${ }^{4}$ Note that this is the key assumption: it implies that the first-best correction of the externality is feasible (Pigouvian taxes are feasible).

${ }^{5}$ In particular, it may include a nonlinear income tax.
} 
good. Similarly, the problem of Sandmo (1975) fits directly into this framework with $v(\cdot)$ interpreted as the indirect utility function and $T$ corresponding to the set of commodity taxes other than the tax imposed on the dirty good.

The following proposition is the main result of this note. It shows that the optimal tax structure in the problem with an externality may be expressed as the sum of the Pigouvian tax and optimal taxes in a related problem without externalities. The proof relies on Taylor approximations of the objective function, and it is presented in the appendix.

Proposition 1. (The Principle of Targeting) Assume that $v(\cdot)$ is $C^{3}$ and $I(\cdot)$ is $C^{1}$. Suppose that the optimum of the problem (1) is given by $\left(T^{*}, t^{*}\right)$, with the resulting level of consumption of the externality generating good $X^{*} \equiv X\left(T^{*}, t^{*} ; P, p\right)$, and the corresponding Lagrange multiplier $\mu^{*}$. Furthermore, assume that agents' decisions depend on $p+t$ (and not on $p$ and $t$ separately). Denote the Pigouvian tax rate by $t_{P}^{*}$, where $t_{P}^{*} \equiv-v_{X}\left(T^{*}, t^{*} ; P, p ; X^{*}\right) / \mu^{*}$. Then $\left(T^{*}, t^{*}-t_{P}^{*}\right)$ solves the first order conditions of the following problem (where $s$ is the tax net of the Pigouvian correction):

$$
\max _{t, T} v\left(T, s ; P, p+t_{P}^{*} ; X^{*}\right) \quad \text { s.t. } \quad R^{*}=I\left(T, s, P, p+t_{P}^{*}\right)+s X,
$$

where $R^{*}=R-t_{P}^{*} X^{*}$.

In the problem (2), all externality-related quantities are held constant. The objective function does not depend on the externality - it is evaluated at $X^{*}$, which is constant. Similarly, the Pigouvian tax rate $t_{P}^{*}$ and the new revenue requirement $R^{*}$ are also constant. The price of the externality-creating commodity incorporates the Pigouvian tax, so that it accounts for the social cost of the externality. The revenue requirement is reduced by the revenue collected using the Pigouvian tax. As a result, the problem (2) is a standard second-best problem: the externality is not present, the objective function depends only on prices and taxes, and it is maximized subject to the standard budget constraint.

The proposition states that instead of solving the problem with an externality (i.e., problem 1), one may equivalently solve the modified problem (2), where the externality is not present. Solutions of these two problems differ only by the Pigouvian tax rate. This is exactly the principle of targeting: having found the solution of the problem without externalities, augmenting it by the Pigouvian correction yields a solution to the problem with externalities present. The optimal $T$ and $s$ are affected by the externality only via the impacts of the Pigouvian tax on the price and the revenue requirement in the modified problem. Both are straightforward, mechanical effects. The logic of this solution is the same as in the case of Pigouvian taxation: as soon as prices are adjusted to reflect any damage caused by the externality, standard optimization is all that is required to maximize welfare.

The proof of this proposition relies on the second-order Taylor approximation. This requires only that the objective function is three times continuously differentiable, a mild assumption that economists are usually willing to make. Although there may be other ways of approaching the

\footnotetext{
${ }^{6}$ This is true in almost all optimal taxation models, and will be true as long as there is no tax evasion, no tax avoidance, and administrative issues are not considered. For an example where this assumption is not satisfied, see Slemrod (2001).

${ }^{7}$ This is the same definition as the one used by Sandmo (1975) and Cremer et al. (1998). $t_{P}^{*}$ is equal to the marginal damage due to the externality, evaluated in dollar terms. Note that $t_{P}^{*}$ is a constant, $\mu^{*}$ is positive, and $v_{X}$ is less than zero when one deals with a negative externality, so that $t_{P}^{*}$ is positive.
} 
problem, this one seems natural because differentiability of the objective function is required for the Pigouvian taxes to be well defined. Consequently, there is no significant loss of generality due to this assumption.

\section{Conclusion}

It was demonstrated that, as was observed by Sandmo (1975) and Dixit (1985), externalities should be targeted directly using Pigouvian taxation, even when other distortionary taxes are used. Contrary to the previous literature, this result was demonstrated without imposing restrictions on the set of available tax instruments other than the assumption of feasibility of direct taxation of the dirty good. Intuitively, every problem of this sort has a two-part solution. First, calculate the appropriate Pigouvian tax necessary to correct the externality. Then, with the externality accounted for, the usual second-best problem can be solved using standard formulae, ignoring the externality, but taking into account both the revenue generated by the Pigouvian tax and the modified price of the externalitygenerating good.

Although the approach is quite general, this conclusion may break down when issues involving tax avoidance, evasion, and administrative costs are introduced. The approach also ignores general equilibrium consideration.

\section{Acknowledgements}

I thank Roger Gordon, Joel Slemrod and Alick Zamouline for helpful comments.

\section{Appendix A. Proof of Proposition 5}

Take Taylor expansions of the objective function in the problem (1) twice. First expand $v$ around $X^{*}$, and then expand $v_{X}$ around $\left(t^{*}, T^{*}\right)^{8}$

$$
\begin{aligned}
v(T, t ; P, p ; X)= & v\left(T, t ; P, p ; X^{*}\right)+v_{X}\left(T, t ; P, p ; X^{*}\right)\left(X-X^{*}\right)+\text { h.o.t. } \\
= & v\left(T, t ; P, p ; X^{*}\right)+v_{X}\left(T^{*}, t^{*} ; P, p ; X^{*}\right)\left(X-X^{*}\right) \\
& +v_{X T}\left(T^{*}, t^{*} ; P, p ; X^{*}\right)\left(X-X^{*}\right)\left(T-T^{*}\right) \\
& +v_{X t}\left(T^{*}, t^{*} ; P, p ; X^{*}\right)\left(X-X^{*}\right)\left(t-t^{*}\right)+\text { h.o.t. } \\
= & v\left(T, t ; P, p ; X^{*}\right)+v_{X}\left(T^{*}, t^{*} ; P, p ; X^{*}\right)\left(X-X^{*}\right)+\text { h.o.t., }
\end{aligned}
$$

\footnotetext{
${ }^{8}$ When vector $T^{*}$ is not finite-dimensional, an analogous argument could be made by considering variations about the optimal $T^{*}$ or by approximating the nonlinear instrument by sums of linear ones.
} 
where 'higher order terms' (h.o.t.) refer to terms of at least quadratic order. Note that $v_{X}=-\mu t_{P}^{*}+$ $\left(\mu-\mu^{*}\right) t_{P}^{*}$ and express the Lagrangian as ${ }^{9}$

$$
\begin{aligned}
\mathscr{L}= & v\left(T, t ; P, p ; X^{*}\right)-\mu\left(R-t_{P}^{*} X^{*}-I(T, t ; P, p)-\left(t-t_{P}^{*}\right) X\right) \\
& +t_{P}^{*}\left(\mu-\mu^{*}\right)\left(X-X^{*}\right)+\text { h.o.t. }
\end{aligned}
$$

Note that $t_{P}^{*}\left(\mu-\mu^{*}\right)\left(X-X^{*}\right)$ is of the second order, and thus is a 'higher order term'. At this point, it is useful to change variables, letting $s \equiv t-t_{P}^{*}$. One can equivalently maximize the objective function with respect to $s$ instead of $t$

$$
\mathscr{L}=v\left(T, s+t_{P}^{*} ; P ; p ; X^{*}\right)-\mu\left(R-t_{P}^{*} X^{*}-I\left(T, s+t_{P}^{*} ; P, p\right)-s X\right)+\text { h.o.t. }
$$

By assumption, one may account for $t_{P}^{*}$ as a part of the price instead of the tax. We reach the final version of the Lagrangian (denoting as $R^{*} \equiv R-t_{P}^{*} X^{*}$ ):

$$
\mathscr{L}=v\left(T, s ; P, p+t_{P}^{*} ; X^{*}\right)-\mu\left(R^{*}-I\left(T, s ; P, p+t_{P}^{*}\right)-s X\right)+\text { h.o.t. }
$$

This is still the Lagrangian for the problem (1). In particular, $(T, s, \mu)=\left(T^{*}, s^{*}, \mu^{*}\right), s^{*}=t^{*}-t_{P}^{*}$, must be its solution. First derivatives of (A.4) at $\left(T^{*}, t^{*}-t_{P}^{*}, \mu^{*}\right)$ do not depend on derivatives of the higher-order terms because they are all zeros (because all expansions took place around either $X^{*}$, $\left(T^{*}, t^{*}\right)$, or $\left.\mu^{*}\right)$. Thus, $\left(T^{*}, s^{*}, \mu^{*}\right)$ satisfies also the first order conditions for an optimum of ${ }^{10}$

$$
M=v\left(T, s ; P, p+t_{P}^{*} ; X^{*}\right)-\mu\left(R^{*}-I\left(T, s ; P, p+t_{P}^{*}\right)-s X\right),
$$

which is the Lagrangian for problem (2).

\section{References}

Bovenberg, A.L., de Mooij, R.A., 1994. Environmental levies and distortionary taxation. American Economic Review 84 (4), 1085-1089.

Bovenberg, A.L., Goulder, L.H., 1996. Optimal environmental taxation in the presence of other taxes: general equilibrium analyses. American Economic Review 86 (4), 985-1000.

Bovenberg, A.L., van der Ploeg, F., 1994. Environmental policy, public finance and the labour market in a second best world. Journal of Public Economics 55 (3), 349-390.

Cremer, H., Gahvari, F., Ladoux, N., 1998. Externalities and optimal taxation. Journal of Public Economics 70 (3), $343-364$. Dixit, A.K., 1985. In: Auerbach, A.J., Feldstein, M.S. (Eds.). Tax Policy in Open Economies, in Handbook of Public Economics, Vol. 1. North-Holland, Amsterdam; New York, pp. 313-374.

Fullerton, D., 1997. Environmental levies and distortionary taxes: comment. American Economic Review 87 (1), $245-251$. Green, J., Sheshinsky, E., 1976. Direct versus indirect remedies for externalities. Journal of Political Economy 84 (4), 797-808.

\footnotetext{
${ }^{9}$ Differentiability assumptions in the statement of the proposition guarantee that this is a valid approach to this optimization problem.

${ }^{10}$ There is no guarantee that $\left(T^{*}, s^{*}\right)$ is the global maximum of this problem, even though it was assumed to be the global maximizer of the original one.
} 
Ng, Y.K., 1980. Optimal corrective taxes or subsidies when revenue raising imposes an excess burden. American Economic Review 70 (4), 744-751.

Sandmo, A., 1975. Optimal taxation in the presence of externalities. Swedish Journal of Economics 77 (1), $86-98$.

Slemrod, J., 2001. A general model of the behavioral response to taxation. International Tax and Public Finance 8 (2), 119-128. 